\title{
Role of echocardiography for assessment of cardiovascular haemodynamics during pregnancy
}

\author{
Sonali S. Somani ${ }^{1}$, Sunandini $\mathbf{R}^{2}$, Shashikant G. Somani ${ }^{3} *$ \\ ${ }^{1}$ Department of Obstetrics \& Gynaecology,Kamineni Institute of Medical Science, Narketpally, Nalgonda (Dist) \\ Telangana, India \\ ${ }^{2}$ Department of Physiology, Osmania Medical College, Hyderabad, Telangana, India \\ ${ }^{3}$ Department of Physiology, Kamineni Institute of Medical Science, Narketpally, Nalgonda (Dist), Telangana, India
}

Received: 23 October 2015

Accepted: 12 December 2015

\author{
*Correspondence: \\ Dr. Shashikant G Somani, \\ E-mail: drsgsomani@gmail.com
}

Copyright: $\odot$ the author(s), publisher and licensee Medip Academy. This is an open-access article distributed under the terms of the Creative Commons Attribution Non-Commercial License, which permits unrestricted non-commercial use, distribution, and reproduction in any medium, provided the original work is properly cited.

\begin{abstract}
Background: Pregnancy is associated with volume overload producing significant vascular and hemodynamic adaptations in cardiovascular physiology. Present study was designed to follow up gradual adaptations in cardiovascular hemodynamics during the course of pregnancy using Doppler echocardiography which is reproducible and noninvasive technique.

Methods: In present prospective study of 50 women, were divided into 2 groups of 25 each: control group \& study group (pregnant patient in I trimester, II trimester \& III trimester). They were non-invasively analysed for cardiovascular function and systemic hemodynamics using echocardiography and compared with control group. The data was analysed using ANOVA for comparison within the group and student's t- test for comparison between the groups. $\mathrm{p}$ value $<0.05$ was considered to be significant.

Results: Mean age and height in control and study groups were comparable. Weight gain was within the expected range with advancement of pregnancy. Heart rate was increased in I and II trimesters with peak rise in III trimester. The difference between control group and study groups was statistically significant $(\mathrm{p}<0.05)$. Systolic blood pressure was slightly decreased in all the trimesters as compared to control group which was statistically not significant. There was gradual increase in SBP from I to III trimesters. Diastolic blood pressure progressively decreased in I and II trimesters and then increased in III trimester. The difference in DBP between control group and I, II trimesters of pregnancy was significant $(\mathrm{p}<0.05)$.Systemic vascular resistance progressively decreased with advancement of pregnancy and difference was statistically significant $(\mathrm{p}<0.05)$. Cardiac output is steadily increased in all trimesters of pregnancy with peak at 36 weeks and was statistically significant $(\mathrm{p}<0.05)$. It was due to increase in both heart rate and Stroke volume. Ejection fraction also increased in all trimesters.

Conclusions: Present study shows significant functional changes in the cardiovascular dynamics during pregnancy. Doppler echocardiography provides an excellent noninvasive method for the evaluation and serial analysis of hemodynamic changes. These results will help in distinguishing abnormal echocardiographic changes from the normal physiologic changes of pregnancy. Therefore maternal echocardiography should be introduced into the antenatal management protocol, which will help to identify women at high risk to developing cardiovascular complications and there by early intervention.
\end{abstract}

Keywords: Pregnancy, Echocardiography, Hemodynamics 


\section{INTRODUCTION}

Pregnancy is a physiological phenomenon. It produces both anatomical and physiological changes in all the organs including reproductive organs, cardiovascular system, hemopoietic system, respiratory system and excretory system etc. The understanding of these adaptations is important for applied Physiology.

Pregnancy is associated with volume overload producing significant vascular and hemodynamic adaptations in cardiovascular physiology. ${ }^{1}$ They are necessary for successful pregnancy, but they impose further load on the heart. Moreover, heart disease is the leading cause of nonobstetric mortality during pregnancy, and the number of pregnant women at risk for cardiovascular complications is on the rise. ${ }^{2,3}$ Therefore, understanding of maternal cardiac function allows clinicians to detect and manage cardiac disease during early stages. In earlier days, gas exchange techniques were used to determine cardiac output. With development of cardiac catheterization, studies were performed using right heart hemodynamics. The advent of echocardiography enabled serial noninvasive cardiovascular monitoring throughout pregnancy. Initially, investigators used M-mode but perhaps due to its limitations, results were not uniform. ${ }^{4}$ Recently, Doppler echocardiography has been used which is reproducible and non-invasive technique suitable for pregnant women. ${ }^{5}$ Therefore present study was designed to follow up gradual adaptations in cardiovascular hemodynamics during the course of pregnancy using Doppler echocardiography.

\section{METHODS}

Present study was conducted at Department of Obstetrics and Gynecology in Kamineni Institute of Medical Sciences, Narketpally Nalgonda District, Telangana in collaboration with Department of Cardiology. It was prospective case controlled study conducted in 50 subjects during August 2014 to September 2015 over a period of 14 months.

In present study, 25 healthy pregnant women with singleton pregnancy (study group) between 20-30 years were compared with 25 age matched non-pregnant women as control group.

Patients who refused to participate, those suffering from cardiovascular disease, diabetes mellitus, thyroid disorder, anaemia and pregnant women with multiple gestation and toxemia of pregnancy were excluded.

All subjects were informed in detail about aim, objectives and the procedure of the study; and written consent was taken for conduct of study.

In present study, total 32 pregnant women were enrolled during first trimester, out of which seven were dropped out due to reasons like abortion, development of pregnancy induced hypertension, lack of follow up and poor quality images etc. Thus finally, twenty five pregnant women were involved in the study.

The study was performed in 3 sessions; First between 1012 weeks of gestation, Second between 24-28 weeks of gestation and third between 34-36 weeks of gestation. Non pregnant woman were studied for single time.

A detailed obstetric history in pregnant women and thorough examination was done in all subjects. Age was noted. Height was measured, with accuracy of 0.5 $\mathrm{cm}$.Weight was measured, up to nearest $100 \mathrm{gm}$.

Blood pressure was measured by sphygmomanometer in right arm in left lateral position after 10 minutes of rest by auscultatory method. Onset of tapping sound was taken as systolic and muffling of Korotkoff sound was taken as diastolic blood pressure. Three measurements were done at 5 minutes interval and average was taken. Mean arterial pressure (MAP) was calculated as diastolic pressure $+1 / 3$ pulse pressure.

An obstetric ultrasound scan, was performed in pregnant woman to confirm singleton pregnancy and gestational age.

All subjects were subjected to echocardiography using Philips ANVISER-C model. Standard parasternal two dimensional long axis images were recorded and left ventricular diameters were measured in $\mathrm{M}$ mode (American Society of Echocardiography guidelines). ${ }^{6}$

Doppler Echocardiography was used to calculate the stroke volume. ${ }^{7}$ Simultaneously heart rate per minute was recorded by electrocardiograph. Cardiac output (CO) (L/min) was calculated by multiplying stroke volume (L) and heart rate (beats/min).

Systemic vascular resistance (SVR) was calculated as MAP x 80/CO.

Left ventricular systolic function was assessed by measuring ejection fraction (EF) which was calculated as (LV end diastolic volume - LV end systolic volume)/LV end-diastolic volume.

\section{Statistical analysis}

The data was expressed as Mean \pm S.D and was analysed using one way analysis of variance (ANOVA) for comparison within the group and student's t- test for comparison between the groups. P-value $<0.05$ was considered to be significant.

\section{RESULTS}

Age and height was comparable in both the groups (Table 1). Weight gain was within the expected range for all patients with peak in late gestational weeks (Table 2). 
Table 1: Comparison of mean age and mean height of control and study groups $(n=50)$.

\begin{tabular}{|c|c|c|c|}
\hline & $\begin{array}{l}\text { Control group } \\
(\mathbf{n}=25)\end{array}$ & $\begin{array}{l}\text { Study group } \\
(\mathrm{n}=25)\end{array}$ & $\begin{array}{l}\mathrm{p} \\
\text { value }\end{array}$ \\
\hline $\begin{array}{l}\text { Mean age } \\
\text { (years } \pm S D)\end{array}$ & $25.94 \pm 4.08$ & $24.91 \pm 4.24$ & $>0.05$ \\
\hline $\begin{array}{l}\text { Mean height } \\
(\mathrm{cm} \pm \mathrm{SD})\end{array}$ & $153.34 \pm 3.68$ & $152.08 \pm 3.55$ & $>0.05$ \\
\hline
\end{tabular}

Heart rate is increased in $1^{\text {st }}$ and $2^{\text {nd }}$ trimesters with peak rise in $3^{\text {rd }}$ trimester. The difference between control group and study groups was statistically significant $(\mathrm{p}<0.05)$.

Systolic blood pressure was slightly less in all the trimesters as compared to control group which was statistically not significant. There was gradual increase in SBP from I to III trimesters (Table 3).
Table 2: Mean weight of control and study groups $(\mathbf{n}=\mathbf{5 0})$.

\begin{tabular}{|llll|}
\hline Mean Weight & \multicolumn{2}{l|}{$(\mathrm{Kg} \pm \mathrm{SD})$} \\
\hline $\begin{array}{l}\text { Control } \\
\text { group }(\mathrm{n}=25)\end{array}$ & \multicolumn{2}{l|}{ Study group $(\mathrm{n}=25)$} \\
\cline { 2 - 4 } & I Trimester & II Trimester & III Trimester \\
\hline $44.42 \pm 2.66$ & $46.38 \pm 3.17$ & $51.52 \pm 3.12$ & $56.44 \pm 3.01$ \\
\hline
\end{tabular}

As pregnancy advances, there was increase in the weight.

Diastolic blood pressure progressively decreased in I and II trimesters and then increased in III trimester. The difference in DBP between control group and I, II trimesters of pregnancy was significant $(\mathrm{p}<0.05)$ (Table 3).

MAP decreased significantly in first trimester as compared to control group, then gradually increased till third trimester (Table 3 ).

Table 3: Comparison of heart rate and blood pressure between study and control group ( $\mathbf{n = 5 0})(\mathrm{Mean} \pm \mathrm{SD})$.

\begin{tabular}{|lllll|}
\hline & Control Group $(\mathbf{n}=25)$ & & \multicolumn{2}{l|}{ Study Group $(\mathbf{n}=25)$} \\
\hline & & I Trimester & II Trimester & III Trimester \\
\hline Heart rate (Beats/min) & $79.3 \pm 4.7$ & $91.6 \pm 5.1^{*}$ & $93.3 \pm 3.8^{*}$ & $97.6 \pm 4.1^{*}$ \\
\hline Systolic blood pressure $(\mathrm{mmHg})$ & $109.31 \pm 6.2$ & $101.2 \pm 5.7^{*}$ & $104.21 \pm 7.1$ & $107.32 \pm 6.9$ \\
\hline Diastolic blood pressure $(\mathrm{mmHg})$ & $76.5 \pm 5.1$ & $66.33 \pm 4.7^{*}$ & $62.66 \pm 5.2^{*}$ & $71.5 \pm 5.1$ \\
\hline Mean arterial pressure $(\mathrm{mmHg})$ & $87.4 \pm 5.2$ & $77.97 \pm 4.2^{*}$ & $76.51 \pm 4.9 *$ & $83.44 \pm 4.8$ \\
\hline
\end{tabular}

$* \mathrm{p}<0.05$ - significant as compared to control.

SVR progressively decreased with advancement of pregnancy and difference was statistically significant $(\mathrm{p}<0.05)$ as compared with control group (Table 4).Cardiac output is steadily increased in all trimesters of pregnancy with peak at 36 weeks and was statistically significant $(\mathrm{p}<0.05) \quad($ Table 4).Ejection fraction was increased in all trimesters (Table 4).

Table 4: Comparison of echocardiographic parameters between study and control group $(\mathrm{n}=50)(\mathrm{Mean} \pm \mathrm{SD})$.

\begin{tabular}{|lllll|}
\hline Parameter & Control group $(\mathrm{n}=25)$ & \multicolumn{2}{l|}{ Study group $(\mathrm{n}=25)$} & \\
& & I Trimester & II Trimester & III Trimester \\
\hline Stroke volume $(\mathrm{ml})$ & $60.04 \pm 5.1$ & $62.2 \pm 6.2$ & $67.7 \pm 5.6^{*}$ & $71.4 \pm 5.8^{*}$ \\
\hline Cardiac output $(\mathrm{lt} / \mathrm{min})$ & $4.76 \pm 0.4$ & $5.69 \pm 0.47^{*}$ & $6.32 \pm 0.56^{*}$ & $6.97 \pm 0.52^{*}$ \\
\hline Systemic vascular resistance $\left(\right.$ dyne.sec $\left.\mathrm{cm}^{-5}\right)$ & $1468.91 \pm 112$ & $1096.2 \pm 125^{*}$ & $968.48 \pm 119^{*}$ & $957.7 \pm 131^{*}$ \\
\hline Ejection fraction $(\%)$ & $68.31 \pm 5.1$ & $73.72 \pm 4.7$ & $79.26 \pm 4.3^{*}$ & $74.71 \pm 5.7$ \\
\hline
\end{tabular}

$* \mathrm{p}<0.05$ - significant as compared to control.

\section{DISCUSSION}

Present study was designed to follow gradual adaptations in hemodynamics during the course of pregnancy.

Age and height was comparable in both the groups.
Weight gain was within the expected range for all patients with peak in late gestational weeks. This is in agreement with other authors but the mean values of anthropometry were lower which may be attributed to ethnic and racial differences between the study population. $^{8,9}$ 
Pregnancy is a condition of primary peripheral arterial vasodilation, associated with hyperdynamic circulation with high $\mathrm{CO}$ and low SVR. ${ }^{1}$

In present study, heart rate is increased in $1^{\text {st }}$ and $2^{\text {nd }}$ trimesters with peak rise in $3^{\text {rd }}$ trimester. The difference between control group and study groups was statistically significant $(\mathrm{p}<0.05)$.

The increase of heart rate in pregnancy is due to increased metabolism to meet demands of foetus, placenta, increased BMR and oxygen consumption, Bainbridge reflex mechanism (during pregnancy venous return increases, cardiac chambers are distended which initiate cardio acceleratory increase in heart rate) and increase in sympathetic activity due to physiological stress. ${ }^{10}$

Results are in accordance with studies done by various authors. ${ }^{10-14}$

In present study, systolic blood pressure was slightly less in all the trimesters as compared to control group which was statistically not significant. There was gradual increase in SBP from I to III trimesters.

Diastolic blood pressure progressively decreased in I and II trimesters and then increased in III trimester. The difference in DBP between control group and I, II trimesters of pregnancy was significant $(\mathrm{p}<0.05)$. The fall in pressure is due to reduction in vascular tone mediated by progesterone and increase in prostacyclin level. ${ }^{15}$

MAP decreased significantly in first trimester as compared to control group and then gradually increased till third trimester. Similar observations were noticed by other researchers. ${ }^{12,14,16,17}$ Though systolic BP increased in II trimester, fall in diastolic BP in I and II trimester, kept MAP at steady level. In III trimester MAP increased parallel to diastolic BP. SVR progressively decreased with advancement of pregnancy and difference was statistically significant $(\mathrm{p}<0.05)$ as compared with control group.

Different mechanisms have been proposed to explain these changes. Nitric oxide (NO), the vascular smooth muscle relaxing substance acts through cGMP mediated vasodilatation. Enzyme endothelium derived nitric oxide synthase (eNOS) plays important role in its production. Biologically it is present in two isoforms i.e. $\mathrm{ca}^{++}$ dependent and $\mathrm{ca}^{++}$independent. Increase in estradiol levels during pregnancy increases activity of $\mathrm{ca}^{++}$ dependent eNOS. ${ }^{18}$ Also high levels of estrogen and progesterone metabolites (5- $\alpha$ dihydroprogesteron) during pregnancy increases arterial refractoriness to angiotensin II. Increased secretions of ANP by heart in response to atrial distention contribute to vasodilatation which is also mediated by cGMP. ${ }^{19}$ In normal pregnancy vascular relaxation in peripheral artery and enhanced arterial compliance in conduit arteries plays crucial role in accomodating increased intravascular volume without increase in blood pressure. $^{20}$

This also explains progressive fall in systemic vascular resistance as pregnancy advances.

Changes in SVR are similar to other studies. ${ }^{11,12,20,21}$

In present study, cardiac output is steadily increased in all trimesters of pregnancy with peak at 36 weeks and was statistically significant $(\mathrm{p}<0.05)$.

It is due to increase in both heart rate and Stroke volume. Increase in the SV seems to be secondary to the increased venous return by plasma volume expansion during pregnancy. Some authors suggests volume gain is due to activation of rennin angiotensin system (RAS) induced by primary peripheral vasodilatation. Because of increase in venous return end diastolic volume increase. ${ }^{22}$ According to Starlings law, with increase in end diastolic volume, there is increase in preload and initial length of cardiac muscle fiber increases with resultant increase in cardiac output.

HR increases initially to compensate relative hypovolumia, in later weeks of pregnancy, high HR is necessary to circulate extra volume. The raised levels of plasma T3 caused by estrogen induced increased TBG and thyrotrophic activity of HCG contributes to increase HR during pregnancy.

Cardiac output was significantly increased even in the first trimester which was mainly due to increase in the heart rate. Similar trends of increase in cardiac output corresponds well with previous reports. ${ }^{11-14}$

Desai et al found Cardiac output increased predominantly in the latter half of pregnancy with peak of $46-51 \%$ occurred from a $15 \%$ increase in heart rate and $24 \%$ increase in stroke volume. ${ }^{8}$

The mean cardiac output of present study are less than other studies, which may be attributed to ethnic and racial differences between the study population, as maternal weight, height and body surface area are lower in Indian women 24.

In the present study, the ejection fraction was increased in all trimesters. Slight increase in the values may be because of the increase in the preload. ${ }^{5}$ Besides this contractile functions of $\mathrm{LV}$ are also influenced by HR and after load. ${ }^{21}$ There was no evidence of LV diastolic dysfunction during pregnancy by Doppler assessment.

Robson et al stated that several studies have shown increase in ejection fraction during pregnancy. ${ }^{5}$ Similar change was observed by other workers. ${ }^{9,20}$ Thus all hemodynamic parameters showed significant changes during pregnancy. 
Thus heart has a universal adaptation response to chronic volume-overload in pregnancy with major hemodynamic changes like sodium and water retention leading to blood volume expansion, an increase in cardiac output, increase in ejection fraction and reduction in systemic vascular resistance and systemic blood pressure.

In case of diversions from these readjustments, conditions like pre-eclampsia may predispose or previously unrecognized cardiac disorders may be unmasked.

\section{CONCLUSIONS}

Present study shows significant functional changes in the cardiovascular dynamics. Doppler echocardiography provides an excellent non-invasive method for the evaluation and serial analysis of hemodynamic changes during pregnancy. These results will help in distinguishing abnormal echocardiographic changes from the normal maternal physiologic changes.

Therefore echocardiography if introduced into the routine antenatal protocol, could help to identify women who are at high risk to develop cardiovascular complications and there by early intervention.

\section{Limitation}

Following are the limitations of the present study.

It was performed in a single hospital therefore sample may not be representative of all Indian women. Therefore we recommend a cross-sectional multicentric study to confirm results of present study and to outline reference limits of echocardiographic parameters during pregnancy.

\section{Future}

Further studies can be made by 3D echocardiography which is based on direct volumetric quantification, which is independent of geometric assumption of Left Ventricle and as it is semi-automatic, it is also relatively operator independent.

\section{ACKNOWLEDGEMENTS}

Authors would like to express deep gratitude to all patients. They are grateful to authors, editors and publishers of all those articles, journals and books from where the literature for this article has been reviewed and discussed.

Funding: No funding sources Conflict of interest: None declared

Ethical approval: The study was approved by the Institutional Ethics Committee

\section{REFERENCES}

1. Schrier RW. Pathogenesis of sodium and water retention in high output and low output cardiac failure, nephrotic syndrome and pregnancy. N Engl J Med. 1989;319:1127-34.

2. Presbitero P, Boccuzzi GG, Groot CJM, RoosHesselink JW. ESC textbook of cardiovascular medicine. Oxford: Oxford University Press. 2009.

3. Siu SC, Sermer M, Colman JM, Alvarez AN, Mercier LA, Morton BC et al. Prospective multicenter study of pregnancy outcomes in women with heart disease. Circulation. 2001;104:515-21.

4. Vered Z, Poler SM, Gibson P, Wlody D, Wrez J. Noninvasive Detection of the morphologic and hemodynamic changes during normal pregnancy. Clin Cardiol. 1991;14:327-34.

5. Robson SC, Hunter S, Boys RJ and Dunlop W. Serial study of factors influencing changes in cardiac output during human pregnancy. Am J Physiol. 1989;256:1060-5.

6. Sahn DJ, DeMaria A, Kisslo J, Weyman A. Recommendations regarding quantitation in M-mode echocardiography: results of a survey of echocardiographic measurements. Circulation. 1978;58:1072-83.

7. Van Oppen AC, Stigter RH, Bruinse HW. Cardiac output in normal pregnancy: A critical review. Obstet Gynecol. 1996;87:310-8.

8. Desai DK, Moodley J, Naidoo DP. Echocardiographic assessment of cardiovascular hemodynamics in normal pregnancy. Obstetrics \& Gynecology. 2004;104(1):20-9.

9. Mabie VC, DiSessa TG, Crocker LG, Sibai BM, Arheart KLA. Longitudinal study of cardiac output in normal pregnancy. Am J Obstet Gynecol. 1994; 170(3):849-56.

10. Wilson M, Mongauti AA, Zervondeki I, Letcher RL, Romney BM, Von Oeyon P et al. Blood pressure, the rennin-aldosterone system and sex steroids throughout normal pregnancy. Am J Med. 1980;68(1):97 -107.

11. Bharshankar JR, Kakade CT , Bharshankar RNS, Kale AH . Hemodynamic changes in normal Indian primigravida: Serial evaluation by echocardiography. Int J Biol Med Res. 2012; 3(1):1289-93.

12. Bene RD, Barletta G, Mello G, Lazzeri C, Mecacci F, Parretti E et al. Cardiovascular function in pregnancy: effects of posture. British Journal of Obstetrics and Gynaecology. 2001;108:344-52.

13. Cong J, Fan T, Yang X, Squires JW, Cheng G, Zhang $L$ et al. Structural and functional changes in maternal left ventricle during pregnancy: a threedimensional speckle-tracking echocardiography study. Cardiovascular Ultrasound .2015;13:6.

14. Tso G, Lee J, Lui G, Trivedi H, Cohen M, Bernstein $P$ et al. Range of echocardiographic parameters during normal pregnancy. Montefiore Medical Center, Bronx, NY, JACC . 2012;59(13):534-47. 
15. Hankins GD, Clark SL, UCI Kan E, Van Hook JW. Maternal oxygen transport variables during the third trimester of normal pregnancy. Amj Obstet Gynaecol. 1999;180:406-9.

16. Simmons LA, Gillin AG, Jeremy RW. Structural and functional changes in left ventricle during normotensive and preeclamptic pregnancy. Am J Physiol. 2002;283:1627-33.

17. Schannwell CM, Zimmerman T, Schneppenheim M, plehn G. Left ventricular hypertrophy and diastolic dysfunction in healthy pregnant women. Cardiology.2002;97:73-8.

18. Weiner CP, Lizasoain I, Baylis SA, Knowles RG, Charles IG. Induction of calcium dependent nitric oxide synthases by sex hormone. Proc Natl Acad Sci. 1994;91:5212-6.

19. Cunningham FG, Leveno KJ, Bloom SL et al. In Maternal Physiology. Williams Obstetrics $22^{\text {nd }}$ edn. Mc Graw-Hill. 2005;129:135-6.

20. Poppas A, Shroff SG, Korcarz CE, Hibbard JU. Serial assessment of cardiovascular system in normal pregnancy. Circulation. 1997;95:2407-15.
21. Carbillon L, Uzan M, Uzan S. Pregnancy, vascular tone and maternal hemodynamics: A crucial adaptation. Obstet Gynecol Surv. 2000;55:574-81.

22. Savu O, Jurcuţ R, Giuşcă S, van Mieghem T, Gussi I, Popescu BA et al. Morphological and functional adaptation of the maternal heart during pregnancy, Circ Cardiovasc Imaging. 2012;5(3):289-97.

23. Duvekot JJ, Cheriex EC, Pieters FAA, Paul MPCA, Louis PLH. Early pregnancy changes in volume homeostasis develop as a consequence of preceding changes in maternal hemodynamic. Am Obstet Gynecol. 1993;169(6):1382-92.

24. Gilson GJ, Samaan S, Crawford MH, Qualls CR, Curete LG. Changes in hemodynamics, ventricular remodelling and ventricular contractility during normal pregnancy: A longitudinal study. Obstet Gynecol. 1997;89 (6):957-62.

Cite this article as: Somani SS, Sunandini R, Somani SG. Role of echocardiography for assessment of cardiovascular haemodynamics during pregnancy. Int J Reprod Contracept Obstet Gynecol 2016;5:84-9. 